\title{
Analyzing Job Requirements for College Students in Major of Network Engineering
}

\author{
Jian Wu* \\ Beijing Information Technology College (Eastern Campus), Beijing, China
}

Submission: October 04, 2019; Published: October 16, 2019

*Corresponding author: Jian Wu, Beijing Information Technology College (Eastern Campus), Beijing, China

\begin{abstract}
The rapid progress in internet creates opportunities for companies and enterprises to release their job positions in the recruitment websites, which accumulates large amount of data on recruitment information and creates the need to have some meaningful information extracted from these large volumes of data. This study uses data mining techniques to study the job requirements of network engineering, network administer, and IDC network \& operation, which are the main possible work positions for the college students in major of network engineering. First the percentage of job positions among these three job requirements are calculated, and second the districts with the highest and lowest requirements in job positions of network engineering, network administrator, and IDC network \& operation are presented. The results show that network administrators are the highest requirement of job positions, and the other two jobs requirements are nearly the equal. In the sixteen district of Beijing, Haidian and Chaoyang district has the highest possibilities that student will work at, while Mentougou district has the lowest possibilities. This work provides teachers and course progamme directors with information that might help them to improve the education programmes in the college and provide student with information that might help them to understand which district that they will work at.
\end{abstract}

Keywords: Recruitment information, Network engineering, College students, Data mining

\section{Introduction}

Data mining comes in the first line in the process of information exploration on databases. The purpose of data mining is to extract meaningful knowledge from data [1]. Data mining can be used in education institutes for leading education activities in an effective way, for watching students' performance continuously and directing students in course and profession choosing [2]. Such application of data mining techniques to educational data is referred to as Educational Data Mining (EDM) [3]. There are five primary categories in EDM including prediction, clustering, relationship mining, discovery within models, and distillation of data for human judgment [4]. In order to provide information regarding students' performance to the concerned teachers and study program director to improve the teaching programme, Asif et al. [5] analyzed the performance of students pursuing a 4-year Bachelor degree programme in the discipline of Information Technology by combining three EDM approaches as prediction, clustering and distillation of data for human judgment. Their results indicate that courses can serve as effective indicators of good or poor performance in the degree programme. Course is the foundation of students' career selection after 4 years' education program. Because of the widely use of internet, many companies and enterprises release their recruitment information on job boards, recruitment websites are generating a huge amount of data on recruitment information including positions, requirements and salaries, etc. It is critical to effectively transform this massive collection of data into knowledge which will help teachers, administrators and policy makers to analyze it to enhance decision making. This present study has investigated the recruitment information of network engineering, network administrator, and IDC network \& operation from the recruitment websites with the aim of providing teachers and directors with information that might help them to improve the educational programmes, and providing students with information that might help them to analyze their possible working regions.

\section{Data and Method}

According to the fact that students whose major is network engineering in the Beijing Information Technology College are hunting jobs on network engineering, network administrator, and IDC network \& operation if they graduate from school. The data used in this study comprises recruitment information of these three job positions from recruitment websites in China. We collected recruitment information released for college graduate students in past 3 months in the sixteen districts of Beijing. All 


\section{Civil Engineering Research Journal}

of the raw data were collected by means of web crawler and processed through the cloud computing environment which was installed and tested well in the laboratory of cloud computing technology. Based on the output from the cloud platform, we present and analyzed the results.

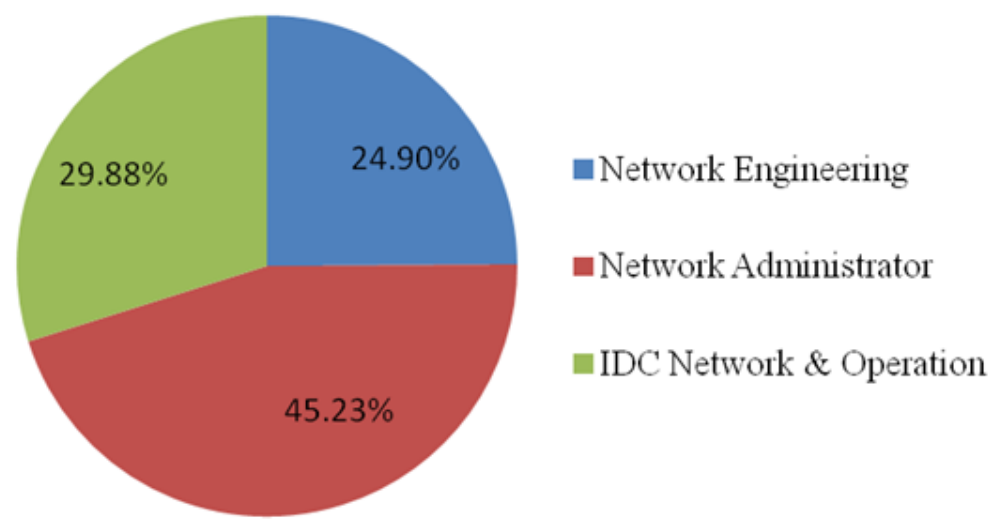

Figure 1: Ratio of the Released Three Job Positions.

\section{Results}

Based on statistic, the job positions provided on network administrator account for nearly half of the three major jobs (Figure 1), while the other two job positions on IDC network \& operation and network engineering were nearly equal. This provides teachers and course programme directors with information that they should pay more attention on courses' design in network administrator.

In addition, the regions of job requirements were presented based on the percent of job requirement numbers. Figure 2 shows the percent of the released job positions in network engineering in the sixteen districts of Beijing. Haidian district has the highest job requirement in network administrator, and followed by Chaoyang, Xicheng, and Fengtai district, while Fangshan, Pinggu and Mentougou district has no job requirement of network engineering. Figures $3 \& 4$ present the situation of job positions of network administrator and IDC network \& operation respectively. Chaoyang and Haidian district are the two highest requirements of jobs in network administrator and IDC network \& operation, while Mentougou district has no requirement of jobs neither for network administrator nor IDC network \& operation.

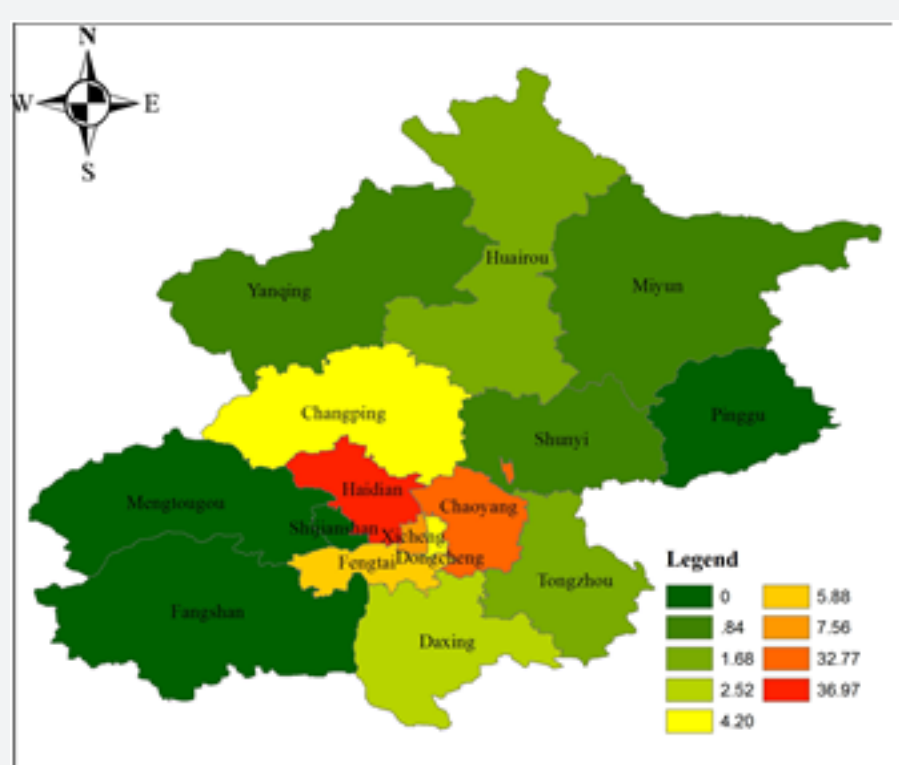

Figure 2: Percent of the Released Job Positions in Network Engineering in Districts of Beijing. 


\section{Civil Engineering Research Journal}

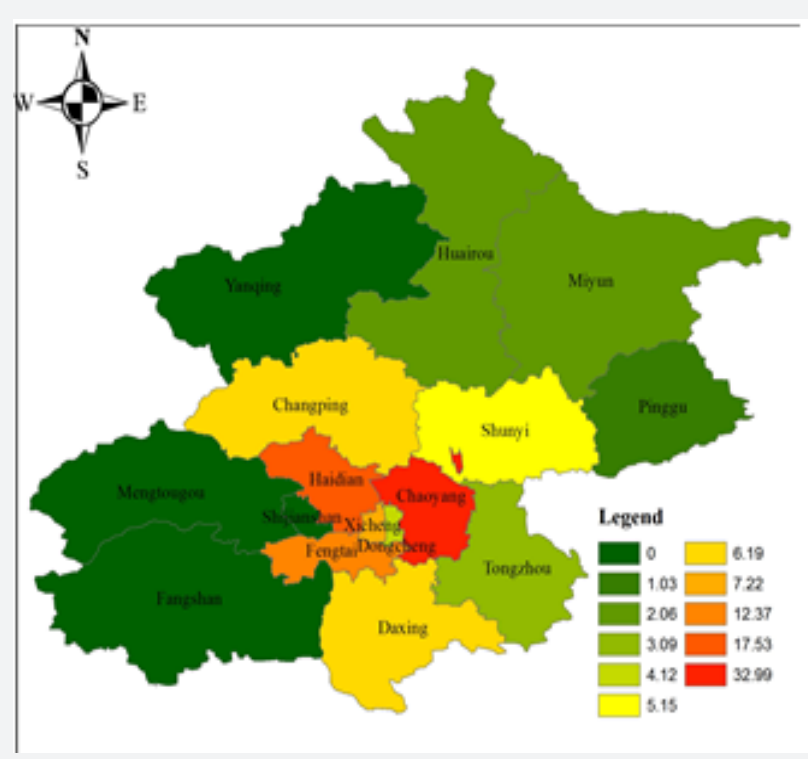

Figure 3: Percent of the Released Job Positions in Network Administrator in Districts of Beijing.

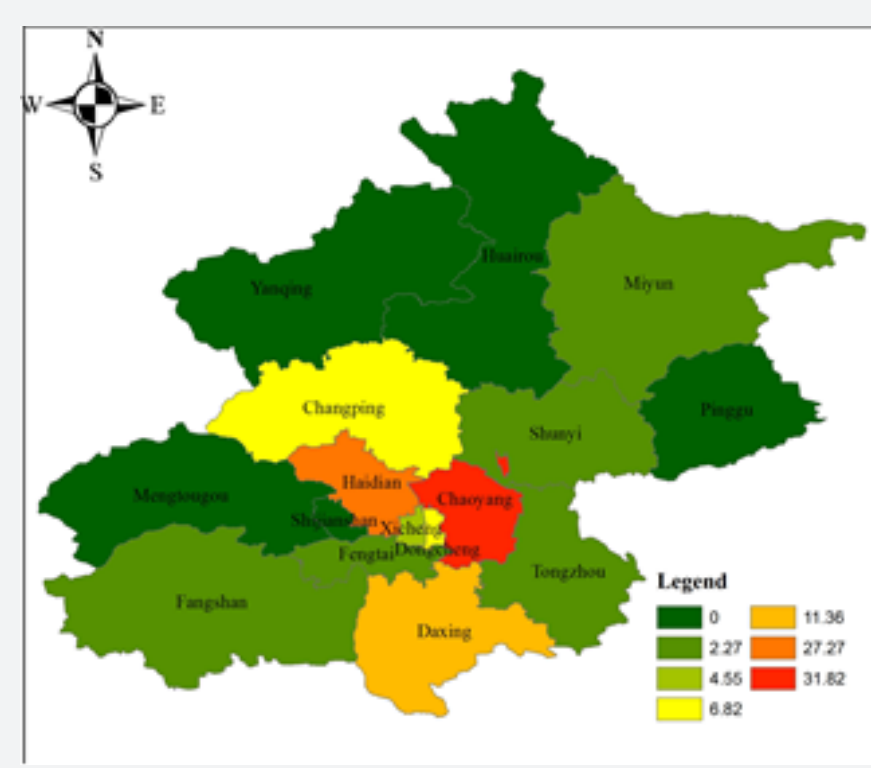

Figure 4: Percent of the Released Job Positions in IDC Network \& Operation in Districts of Beijing.

\section{Conclusion}

This work has collected recruitment information from recruitment websites and analyzed the job requirement percentage in job positions of network engineering, network administrator and IDC network \& operation in districts of Beijing. The goal of this study is to provide teachers and course pregame directors with information that might help them to improve the education programmers in our school and provide student with information that might help them to understand which district that they will work at. The results show that network administrators are the highest requirement of job positions, and the other two are nearly the equal. As far as districts that students will work at are concerned, Haidian and Chaoyang district has the highest possibilities that student will work at, while Mentougou district has the lowest possibilities in the sixteen district of Beijing.

\section{References}

1. Han J, Kamber M (2006) Data mining concepts and techniques $\left(2^{\text {nd }}\right.$ edn.). San Francisco: Morgan Kaufmann, USA.

2. Buldu A, Üçgün K (2010) Data mining application on students' data. Procedia Social and Behavioral Sciences 2: 5252-5259.

3. Baker RSJD, Yacef K (2009) The state of educational data mining in 2009: A review and future versions. Journal of Educational Data Mining 1(1): 3-16. 


\section{Civil Engineering Research Journal}

4. Bower AJ (2010) Analyzing the longitudinal K-12 grading histories of entire cohorts of students: Grades, data driven decision making, dropping out and hierarchical cluster analysis. Practical Assessment, Research \& Evaluation 15(7): 1-18.

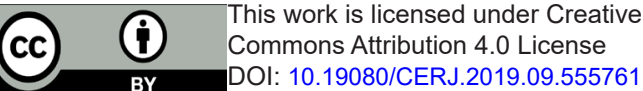

5. Asif R, Merceron A, Ali SA, Haider NG (2017) Analyzing undergraduate students' performance using educational data mining. Computers \& Education 113: 117-194.

\section{Your next submission with Juniper Publishers} will reach you the below assets

- Quality Editorial service

- Swift Peer Review

- Reprints availability

- E-prints Service

- Manuscript Podcast for convenient understanding

- Global attainment for your research

- Manuscript accessibility in different formats ( Pdf, E-pub, Full Text, Audio)

- Unceasing customer service

Track the below URL for one-step submission https://juniperpublishers.com/online-submission.php 